\title{
CUSTOMER SERVICE STANDARDS
}

\section{Venelin Tarziev $^{1 \star}$, Vanya Banabakova ${ }^{2}$, Marin Georgiev ${ }^{3}$}

${ }^{1}$ Corresponding Member of the Russian Academy of Natural History, Moscow, Russia, Prof. D.Sc.(Ec.), D.Sc. (National Security), Ph.D., National Military University, Veliko Tarnovo, Bulgaria; University of Rousse, Rousse, Bulgaria, email: terziev@skmat.com;

2Prof. Ph.D., National Military University, Veliko Tarnovo, Bulgaria, email:v.banabakova@abv.bg; ${ }^{3}$ Ph.D. student, National Military University, Veliko Tarnovo, Bulgaria, email: clementon@abv.bg. ${ }^{*}$ Corresponding author

\begin{abstract}
Ensuring effective customer service requires targeted efforts in a number of areas, one of which is to develop service standards for each market segment

Differentiating customer service is achieved by adopting different standards according to the following criteria: availability of assortment varieties and quantities in percentage of orders placed; actually delivered quantities and assortment varieties in percent of the ordered ones; time (cycle) to execute orders in hours or days, and more.

The development of service standards uses the results of its analyzes and assessments.

Standards relating to customer service should be developed in the following areas: responsibilities of management; quality control system; supplier's obligations; design management; document management; purchase quality; product identification; management of the processes of providing services; customer service quality assessment; management of control, measuring and implementation equipment; corrective actions applied in the case of established discrepancies in the provided services; loading, unloading, storing, packaging, delivery and storage of the product; customer interaction; control over data related to service quality; internal audits related to service quality; personnel training; statistical methods.

The development and implementation of standards requires the organization to accurately determine customer service types, the cost of providing alternative services, and measures for measuring and controlling the services provided.

At the core of the developed and implemented standards is the development and establishment of the customer service policy, which should start with a consumer demand analysis.

The definition of customer service level should allow for quantitative measurement because the vague and quantifiable policy does not provide opportunities for evaluation and control of the activities and expenses of customer service.
\end{abstract}

When developing service standards, it is appropriate to apply an algorithm that focuses primarily on standards related to employee behavior towards customers.

This paper explores the need and capability to develop customer service standards and provides an algorithm for developing standards for employee behavior toward customers.

Keywords: customer service, standards, custom requirements. 


\section{INTRODUCTION}

Ensuring effective customer service requires targeted efforts in a number of areas, one of which is to develop service standards for each market segment (Banabakova, 2013, p. 20)

Customer serving standards are defined parameters that have a quantitative expression. They are valid for a longer period of time, they are pre-bid and refer to all customers in a given category (if the organization has adopted a system for categorizing their customers). They facilitate the execution of orders and related procedures. Standards serve to plan the necessary conditions, operations and procedures, as well as to conclude long-term contracts with permanent clients for their service.

According to Naydenov, service standards include a description of the customer's desired service, the operations that staff should perform and the way they are performed. They should also contain criteria for assessing the quality of work of the staff. The evaluation is carried out by comparing the requirements of the standard with the actual results (Naydenov, 1999, p. 105)

The purpose of this study is to investigate the need and capability to develop customer service standards and to propose an algorithm for developing standards related to employee behavior towards customers.

\section{DEVELOPING CUSTOMER SERVICE STANDARDS}

Differentiating customer service is achieved by adopting different standards according to the following criteria: (Vasileva, 2002, p. 299]

- availability of assortment varieties and quantities in percentage from orders placed;

- quantities actually delivered and assortment varieties in percentage to the ordered ones;

- time (cycle) to execute orders in hours or days, and more.

The development of service standards uses the results of its analyzes and assessments. Service standardization is an activity of unifying plans, processes, planning system, data exchange system, document turnover, cargo units, commercial and transport packaging, etc. Good practices are regulated in standards (ISO international standards) 4, 211-216] Standards relating to customer service should be developed in the following areas: responsibilities of management; quality control system; supplier's obligations; design management; document management; purchase quality; product identification; management of the processes of providing services; customer service quality assessment; management of control, measuring and implementation equipment; corrective actions applied in the case of established discrepancies in the provided services; loading, unloading, storing, packaging, supply and storage of the product; customer interaction; control over data related to service quality; internal audits related to service quality; personnel training; statistical methods.

From a methodological point of view, ISO standards answer the question of what needs to be done to ensure a high level of service, and the question of how to do so is the TQM (Total Quality Management) concept. The latter is geared to improving service when a certain level has already been reached and the implementation of ISO 9000 standards is aimed at reducing the likelihood of deviations. As a result, they complement each other in order to achieve a unified goal, but at different stages of the enterprise's business to provide the necessary level of customer service. The development of ISO 9000 and TQM-based methods is linked to the possibility of integrating the two approaches (Table 1).

Table 1. Conceptual elements of ISO 9000 and TQM

\begin{tabular}{|l|l|l|}
\hline \multirow{2}{*}{ Elements } & \multicolumn{2}{l|}{ Importance for the concept } \\
\cline { 2 - 3 } & ISO 9000 & TQM \\
\hline Leading role of management & Great & Great \\
\hline Creating Workgroups & App. Medium & Great \\
\hline Methods and Instruments & App. Medium & Great \\
\hline Guideline Guidance & Medium & Голямa \\
\hline Official Quality Standards & Great & App. Medium \\
\hline Integrated Quality System & Great & App. Medium \\
\hline Employee Involvement, Credentials, Training & Medium & Great \\
\hline
\end{tabular}

The development and implementation of standards requires the organization to accurately determine customer service types, the cost of providing alternative services, and measures for measuring and controlling the services provided (Ivanov, Zhelezarov, 1999, pp. 128). 
A key element is the analysis of the target market segment, the specific customers, the product (service) / product line, customer service levels, cost, measurement and control over the application of the standards.

At the core of the developed and implemented standards is the development and establishment of the customer service policy, which should start with a consumer demand analysis. It must also take into account the interchangeability of products and the number and characteristics of competitors, as this determines not only the relationship between the organization and customers but also its sales. The need to maintain large stocks and / or use additional transport is the greater the lower the degree of interchangeability of products. The organization should fairly accurately determine customer behavior when needed to fill depleted stocks of specific products as a whole and for the different regional markets.

The consequences of stock depletion are not the same for all customers. They are to a large extent determined by the size of the customer and / or the volume of supplies. Losses in such cases are much greater when dealing with large customers and large deliveries, and this proves to be sufficient basis for implementing a different service policy. In this context, it is often practiced to divide customers by importance into different groups using the $A B C$ analysis method. In the process of conducting these analyzes, specific customer requirements (eg, specific delivery dates) need to be precisely established to accommodate the service. Service policy should be tailored to the current competitive level of service on the market, as lowerlevel tactics places the organization at a disadvantage. However, this also depends on its ability to provide better service at costs that will not significantly affect price competitiveness.

Defining the level of customer service should allow for quantitative measurement because tasks such as "ninety percent customer satisfaction" that are pledged in service policy are not easily measurable and therefore difficult to achieve and control. The ambiguous and not easilily quantifiable policy does not provide opportunities to evaluate and control the activities and costs of customer service. In this respect, quantifiable and traceable indicators and targets for each customer service element should be formulated and quantified in service standards, which can be in the following directions:

- Product availability - usually measured in terms of saturation with a specific product (stock availability percentage) or order execution (stock performance percentage). In the standard for this element, time availability can also be combined to make a measure, such as „ninety-five percent of orders to be delivered on time and in full". Product availability is a critical element of service. Therefore, it is recommended that the company has standards for the number and percentage of correctly executed orders over a certain period of time.

- Order cycle length - It is one of the most frequently treated elements in service standards. It is usually formulated as a percentage of orders executed for a certain number of days after receipt - for example, "ninety-five percent of deliveries made within three days of receipt of the order". To determine the compliance of time standards with customer needs, managers plan cumulative distributions on actual delivery times and compare them with policy-based policies - for example, if $90 \%$ of deliveries within the three days of receipt of the order, the market and customer information for orders received is analyzed to determine how many orders were delivered on time and how much later.

- Flexibility of the logistics system - Defined in service standards as an organization's ability to respond to special customer needs - for example, organizing very fast shipments when needed. In such cases, tasks are specified in the relevant standard, such as „95\% feasibility of fast orders in accordance with customer instructions".

- The information security of the logistics system - It is extremely important for customers. In this regard, the company can formulate its information policy in a relevant standard based on user requirements. The availability of such a standard also facilitates the process of controlling the quality of information of the logistics system.

- Miscarriages in the logistics system - The organization should be able to control and quickly eliminate any deviation with a negative effect on the customer - for example, if a shipment is damaged and can not be used by the customer. Reposting required products requires extra time and is associated with additional costs, which reduces service levels and increases costs. The situation is similar in the case of incorrect invoices as it makes it difficult to establish the amount due.

- After sales support and service - It is an important part of the development of logistics - for example, equipment assembly, complete supply of spare parts and others. In this direction, standards should be set, mainly for the time of delivery of the required spare parts, by formulating real measurable tasks, eg " $95 \%$ of all requested spare parts will be delivered on the day of the order".

In the practical realization of the standardization of the customer service there are also some features: 
First, the parameters set in the standards should be realistically achievable but not too low. It is necessary for the standard to contribute to the effective realization of the existing and potential competitive advantages of the organization.

Second, it is often recommended that service standards be pursued at a level of $100 \%$. This should only be perceived as a philosophy and an ideal, since setting levels below $100 \%$ do not stimulate improvements (Ivanov, Zhelezarov, 1999, pp. 202)

Thirdly, it is advisable that the organization's policy and standards of service be formed and established in close interaction with customers through consultation with them. Practice shows that the best approach is that organizational policy and service standards are open to customers.

Fourthly, the development of procedures for measuring and controlling levels and standards of customer service is a basic prerequisite. Using techniques such as statistical methods of control, maintaining feedback, and undertaking corrective actions are essential to success. If customer service standards are ineffective, the organization should not hesitate to correct or remove them.

It should also be noted that the procurement of raw materials of organizations, as a whole, necessitates reaching almost one hundred percent of service levels because costs related to the depletion of commodity stocks are almost always less than the costs of exhausting stocks of raw materials. In such situations, opportunities are usually sought for replacing raw materials with others. Often, however, the following is observed:

- The short periods for carrying out specific production activities do not allow them;

- A number of raw materials are strictly specialized and specific, their suppliers are limited and replacements are impossible;

- Specific technical and technological requirements make it very difficult for trouble-free replacement.

In this sense, any breach of supply activities may have significant negative consequences for customers (manufacturing enterprises), especially if the depletion of stocks is prolonged. Obviously, the cost of depletion of supply stocks is very high, which requires additional effort on the movement and storage of raw materials. The depletion of stocks of raw materials is linked to causing multiple negative internal and organizational effects - mainly triggering a chain reaction, as the depletion of stocks of raw materials in an enterprise creates problems for the others in the technological chain.

\section{ALGORITHM FOR THE DEVELOPMENT OF THE STANDARDS CONNECTED WITH THE CONDUCT OF OFFICIALS/EMPLOEES TO CUSTOMERS}

When developing service standards in our opinion, it is advisable to apply the following algorithm, which focuses primarily on standards related to employee behavior towards customers: (Golubin, 2007, pp. 65171)

First. Field of application.

Defining the need to create service standards. This need may arise in the following circumstances:

- when the business is related to direct communication with the end user in the context of an intensifying competitive market struggle, whereby pricing policy, the quality of the goods or service being sold and the level of service in the organizations are almost the same. The organization should distinguish itself from its competitors with its approach to customers in order to attract and retain the attention of the desired category of customers;

- When expensive and prestigious products are offered which in themselves require a well- thought approach, representation, delivery and aftercare;

- when the organization has several subdivisions and strives to impose an equally good, familiar and customary style of service regardless of the remoteness of the site from the head office;

- when the aim is to ensure fast and quality control of the high level of service. The tremendous advantage of implementing standards is that they already set those values, which should match the behavior of vendors.

Second. Features of Conversion.

Service standards should be implemented in a comprehensive manner. It is expedient to apply the following ways to implement management elements that provide efficiency:

- preparation of the exact description of the behavior, based on the service standards; 
- training of employees for work habits in accordance with the developed standards;

- Training of specialists managing personnel, to be in line with standards;

- developing a control system to monitor whether employees' actions are in line with standards;

- development of a system for motivation and stimulation of the personnel, who have mastered the standards of service;

- implementing samples - preparation of all documentation (provisions, instructions, quick reference lists) for managers and contractors based on service standards.

Third. Preparation of organizational standards of service.

Stage 1. Description of the employee's actions when interacting with the client.

Task - to prepare an accurate description of the employee's actions based on the relevant service standard sections: telephone conversation; greeting; conducting a dialogue; exit from a prolonged conversation; communication with an inadequate client; arranging accounts with the customer; re-visit (standards of conduct with standing clients); goodbye; behavior of staff in conflict situations.

Order to develop standards:

- Placing a task by the client.

- Surveillance of successful clients' work with the aim of describing the principle consistency of the actions of the employees in the organization (Zhelezarov, 2006).

- Making inquiries among client specialists to clarify opinions on optimal action in line with service standards.

- Conduct a training or seminar with key organizational staff to appraise the standards developed and optimize them.

- Describing the standards in a form for the principle sequence of actions.

- Meeting the project initiators with the clients to reconcile the developed standards.

- Specification of standards with customer wishes.

- Validation of the developed standards.

The result of this stage is the elaboration of a methodical tool describing the actions of the commercial specialist in accordance with the indicated sections of the standard.

Stage 2. Development of a system for controlling the compliance of the employees' behavior with the accepted standards for customer service.

Task - Define a system for obtaining objective information (control) about employees' actions and define a circle of people between the employees in the organization who are responsible for implementing customer service standards.

Order to develop control system:

- Determination of the control criteria, based on the correspondence between the work of the customer care specialist and the service standards.

- Identify a sufficient number of methods for obtaining information to ensure control.

- Development of reporting documentation forms (Letters and Quick Check Lists) for the performance of the functions of control and evaluation of the actions of the specialists.

- Description of actions to assure the objectivity of evaluations of responsible professionals on the control and implementation of the developed standards.

- Description of the control procedure.

- Compiling layouts for the control system in line with customer service standards.

- Conducting a mini-seminar to coordinate the main control points with the specialists responsible for it.

The outcome of this stage should be the development of the Control System Rules.

Stage 3. Changing the motivation of the professionals responsible for the implementation of the standards. 
Task - to incorporate into the motivation system elements that stimulate the actions of the specialists in the company according to the developed standards (Weeraratne, 2016).

Modification of the motivation system:

- All job descriptions are required to include the control of the compliance of employee behavior with service standards.

- Identify and validate incentive rates for those who comply with the standards, but also fines for violations.

- Establish a new pay system.

- Develop and validate incentive rules.

The result of this stage should be Rules for the system for motivation and stimulation of the trade specialists in accordance with the new standards

Stage 4. Implementation of the developed standards.

Task - to explain to staff the appropriateness of adhering to accepted standards. Minimize resistance to change and speed up the process of implementing standards.

Order for implementation of developed standards:

- Conduct meetings with responsible persons to explain the need for strict compliance with the established standards by the employees of the organization. Explain the essence of innovation, give instructions for the actions of those responsible, and clearly outline the sphere of their responsibilities, the level of authority and the resources they can dispose of in their tasks. Answer all questions.

- Some points in customer service standards may be added.

- The result should be focusing on the ability to work with clients in line with accepted standards.

On the basis of this study, the following conclusions are highlighted:

- Standards relating to customer service should be developed in the following areas: responsibilities of management; quality control system; supplier's obligations; design management; document management; purchase quality; product identification; management of the processes of providing services; customer service quality assessment; management of control, measuring and implementation equipment; corrective actions applied in the case of established discrepancies in the provided services; loading, unloading, storing, packaging, supply and storage of the product; customer interaction; control over data related to service quality; internal audits related to service quality; personnel training; statistical methods.

- The basis for the developed and implemented standards is the development and establishment of the customer service policy, which should start with the analysis of consumer demand. It must also take into account the interchangeability of products and the number and characteristics of competitors, as this determines not only the relationship between the organization and customers but also its sales.

- Quantifiable and traceable metrics and targets for each customer service element should be formulated and embedded in service standards.

- In developing service standards, it is appropriate to apply an algorithm that focuses primarily on employee behavior standards for customers, which includes four stages with the appropriate tasks and order for developing the standards.

In conclusion, ensuring quality customer service requires the development and deployment of standards that require the organization to accurately determine customer service levels, the cost of providing alternative services, and the measurement and control measures for the services provided.

\section{REFERENCE LIST}

Banabakova, V. (2013). Logistics as a source of competitive advantages - views and fragmentation. Secondary School of Economics, Veliko Tarnovo, p. 20.

Naydenov, N. (1999). International Marketing. Analysis, strategies, realization. IM "Holding". S., p. 105. 
Vasileva, L. and kol. (2002). Distribution policy. Part 2. Ed. Thrace - MS, p. 299.

Blagoev, Bl. and call. (2009). Industrial logistics. Ed. Science and Economics. University of Economics Varna, pp. 211-216.

Golubin, E. (2007). Effective distribution. Ed. Softpres. S., pp. 165-171.

Zhelezarov, I. S. (2006) Statistical process control by means of Precontrol and measuring means with data output. Facta Universitatis, series: Mechanical engineering. 20 (2).

Ivanov, I., I. Zhelezarov. (1999). Upravlenie na kachestvoto (Chast I - Vtoro preraboteno izdanie) - Osnovi na upravlenieto na kachestvoto, Universitetsko izdatelstvo „Vasil Aprilov”, Gabrovo 1999 g., str.128. (Иванов, И., И. Железаров. (1999). Управление на качеството (Част I - Второ преработено издание) - Основи на управлението на качеството, Университетско издателство „Васил Априлов", Габрово 1999 г., стр.128.).

Ivanov, I. N. i I. S. Zhelezarov. (1999). Upravlenie na kachestvoto (Chast II) - Osnovni instrumenti i statisticheski metodi za upravlenie na kachestvoto, Universitetsko izdatelstvo „Vasil Aprilov” Gabrovo 1999 g., str.202. (Иванов, И. Н. и И. С. Железаров. (1999). Управление на качеството (Част II) Основни инструменти и статистически методи за управление на качеството, Университетско издателство „Васил Априлов” Габрово 1999 г., стр.202.). 